Article

\title{
Pressure Pulsation and Cavitation Phenomena in a Micro-ORC System
}

\author{
Nicola Casari, Ettore Fadiga, Michele Pinelli, Saverio Randi and Alessio Suman * \\ Department of Engineering (DE), University of Ferrara, 44122 Ferrara, Italy; nicola.casari@unife.it (N.C.); \\ ettore.fadiga@unife.it (E.F.); michele.pinelli@unife.it (M.P.); saverio.randi@unife.it (S.R.) \\ * Correspondence: alessio.suman@unife.it
}

Received: 9 May 2019; Accepted: 5 June 2019; Published: 8 June 2019

\begin{abstract}
Micro-ORC systems are usually equipped with positive displacement machines such as expanders and pumps. The pumping system has to guarantee the mass flow rate and allows a pressure rise from the condensation to the evaporation pressure values. In addition, the pumping system supplies the organic fluid, characterized by pressure and temperature very close to the saturation. In this work, a CFD approach is developed to analyze from a novel point of view the behavior of the pumping system of a regenerative lab-scale micro-ORC system. In fact, starting from the liquid receiver, the entire flow path, up to the inlet section of the evaporator, has been numerically simulated (including the Coriolis flow meter installed between the receiver and the gear pump). A fluid dynamic analysis has been carried out by means of a transient simulation with a mesh morphing strategy in order to analyze the transient phenomena and the effects of pump operation. The analysis has shown how the accuracy of the mass flow rate measurement could be affected by the pump operation being installed in the same circuit branch. In addition, the results have shown how the cavitation phenomenon affects the pump and the ORC system operation compared to control system actions.
\end{abstract}

Keywords: micro-ORC; gear pump; CFD; mesh morphing; pressure pulsation; cavitation; dynamic analysis

\section{Introduction}

Over the years several micro-ORC systems have been developed [1] with the aim of understanding and improving the performance of different expander devices, pumping systems, and heat exchanger technology. Despite their effectiveness in energy recovery, micro-ORC systems are characterized by low-efficiency values, especially in cases where the net electric power is less than $10 \mathrm{kWe}$ [2]. In these applications, positive displacement machines are commonly used for expanding and pumping processes [3]. Regarding the expander technology, the review by Bao and Zhao [4] pointed out that, for micro energy systems, the volumetric expander technology is the most preferable in terms of efficiency and cost. In particular, scroll, screw, and rotary vane expanders are the most suitable for micro-ORC systems. When considering ORC systems of net electrical power output around $1 \mathrm{kWe}$, scroll and screw expanders are a well-known technology for energy conversion, but when the temperature of the hot source falls below $100{ }^{\circ} \mathrm{C}$, other machines have to be used. For example, an innovative way to generate a small amount of electrical power (a few Watts) is to utilize free-piston expanders $[5,6]$. From the experimental side, the use of a positive displacement machine requires a specific test-rig to reproduce the actual operating conditions in terms of pressure, fluid characteristics and loads. Commonly, the presence of simplified prototypes and/or different working conditions could determine several differences between the actual machine performance and the measured ones. To help the experimental analysis, a lumped-parameter model is often used for extending the analysis to other 
operating conditions or other fluids $[7,8]$, increasing the design capabilities and limiting the cost and time.

For the pump, no specific indication can be found in the literature, though a greater number of applications are equipped with a positive displacement machine, usually gear pumps. This widespread technology is common adopted for pressurizing the refrigerant (in most cases a certain percentage of oil mass fraction is added to the ORC systems to ensure the proper lubrication of the positive displacement machine) even if the gear pump operation is affected by two main issues, related to the (i) pressure pulsations and (ii) cavitation phenomenon.

Gear pumps are a class of robust positive displacement pumps that can work on a wide range of pressures and rotational speeds, but they are responsible for noise and vibration phenomena that could affect the circuit in which they operate. The damping effects provided by the pipeline are usually not able to eliminate the vibrations [9,10], which are also responsible for disturbances and, sometimes, the damage of measurement devices. Pulsations are due to the pressure ripples provided by the pump, which are driven by the engagement process and the position of the relief grooves [11].

In several applications, micro-ORC systems are equipped with temperature probes, pressure transducers and flow meters. These devices are used to characterize the system and, in addition, for controlling its operating point when external conditions change, such as the electric load and the heat and sink temperature values. Noise and vibrations could, in turn, affect their operations and increase the uncertainty of the measuring process. In particular, the Coriolis flow meter (which is one of the most used technology in micro-ORC test benches) can be greatly affected due to its technology and measuring principle [12]. Despite their accuracy and measuring performance, several analyses have been carried out over the year demonstrating how these devices could be affected by vibrations and pressure pulsations $[13,14]$.

In addition, gear pumps are a class of positive displacement machine that shows high sensitivity to cavitation phenomena, in particular as a function of rotational speed. Higher rotational speed leads to higher volumetric efficiency but, at the same time, the pressure losses and the narrow gaps could cause local pressure drops that could lead to cavitation $[15,16]$. In ORC applications, this phenomenon is even more detrimental due to the thermodynamic state of the liquid pumped. In fact, the refrigerant in this section is very close to the saturated liquid curve and, so, even small pressure variations could originate phase change (from liquid to vapor) at the pump suction section. Cavitation produce erosion issues and is responsible for the reduction of the mass flow rate supplied by the pump. In this case, the control unit of the ORC system has to detect this discrepancy between the expected mass flow rate and the actual one and react by increasing the pump rotational speed.

Given this background, it is easy to understand how the use of a gear pump in a micro-ORC system needs to be analyzed and evaluated according to both the performance and reliability points of view. Pressure pulsations and cavitation affect the ORC system operation and the entire control system. Since these phenomena are mainly due to the pump operation, in this paper a time-dependent computational fluid dynamics (CFD) approach is proposed. The simulation strategy is based on a dynamic mesh approach, able to take into account the rotation and the engagement of the wheels, as well as the transient phenomena that affect the entire ORC. The dynamic mesh approach has been proven to be suitable for the analysis of such a machine, for discovering cavitation issues $[17,18]$ and for calculating the performance $[19,20]$.

The virtual model of the micro-ORC system is taken from an actual installation, described entirely by Bianchi et al. [21]. The capabilities of CFD simulations for analyzing the ORC performance are proven [22,23]; however, in this work, a step forward on the simulation and explanations of such phenomena is performed. The criteria adopted in this paper are defined by the Whole ORC Model (WOM) [22,23], which is a new strategy for improving knowledge in micro-scale energy systems. The WOM strategy concept arises from evidence that the performance of every single device is affected by the operation of the other components/devices that operate in the same system. Including, in the 
same virtual CFD model, a higher number of components allows for an analysis of their interaction and adjusting the control logic, which can be an effective strategy for increasing system reliability.

\section{Aim of the Paper and Novelty}

In this paper, a detailed analysis of pressure pulsation and cavitation phenomenon is carried out by means of transient CFD analysis. The numerical domain considered in the present analysis is depicted in Figure 1 and corresponds to the virtual model of a portion of a real ORC system [21]. As can be seen, starting from the liquid receiver (tank) (which collects the condensed liquid at the condenser outlet), the liquid passes through the Coriolis flow meter (CFM) (which is entirely modeled as reported in the internal view) and is processed by the pump. The pump is installed in the lower part of the circuit and is coupled with the system through an upstream and a downstream valve. The liquid refrigerant is then piped into the regenerator, which has the task of preheating it by removing heat from the refrigerant at the expander outlet. The virtual model depicts the actual installation in a very detailed form: bends, valves and tube-fittings are virtualized, generating a virtual test-bench. The innovative approach for studying the ORC operation reported in the present work is based on the application of a fully 3D transient numerical simulation of the entire system and allows us to analyze:

- the effect of gear pump operation (in terms of pressure pulsation) on the CFM measurement performance. With the dynamic analysis it is possible to extract information about the frequency and magnitude of the vibrations, which can affect the CFM due to the gear pump operation;

- the effect on the pump operation of the actual system layout and design. The virtualization of the ORC systems, which includes valves, bends, tank, regenerator, and measuring device (such as the CFM) allow for the determination of the actual flow conditions (in terms of velocity and pressure) at the inlet port of the gear pump;

- $\quad$ the effect of cavitation on the pump operating points. By coupling the control system strategy and the CFD analysis, it is possible to detect how the cavitation phenomenon affects the ORC operation and which solution can be adopted for improving the control capability of the system, with the aim of preserving the performance and the reliability of each component.

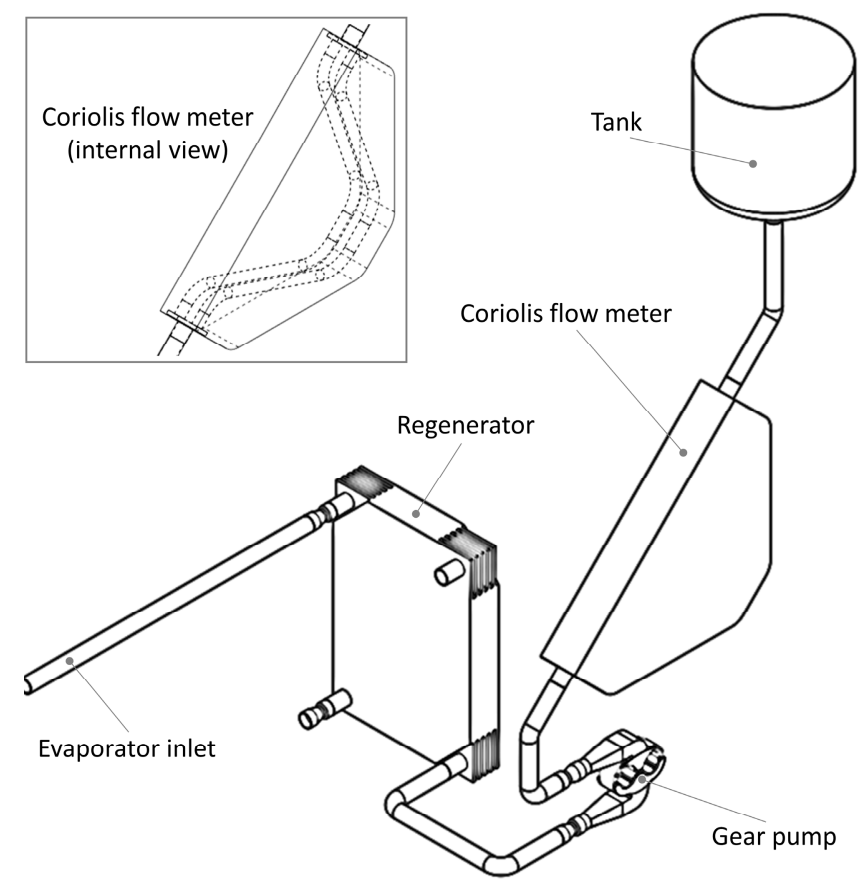

Figure 1. The virtual model of the micro-ORC system: tank, Coriolis flow meter, gear pump, and regenerator. 


\section{Materials and Methods}

As already pointed out, the virtual model of the ORC system is realized with reference to an actual installation. The operating conditions are taken directly from the experimental data described in [21]. The experimental data are used for (i) validating the numerical results and (ii) feeding the numerical model with actual operating conditions, allowing the analysis of specific fluid dynamic effects (cavitation at the gear pump inlet and pressure pulsation on the CFM due to the gear pump operation), which can be difficult to detect by means of an experimental approach.

The prototypal micro-ORC energy system used as a reference was specifically designed for in-field operations but, at the same time, was equipped with several additional sensors/probes in order to detect its operating points and performance. The ORC system operates with R134a as a working fluid and its main components are as follows: (i) a brazed plate heat exchanger with 64 plates as evaporator, (ii) a brazed plate heat exchanger with 16 plates as a regenerator, (iii) a shell and tube heat exchanger as condenser, (iv) a volumetric three-piston radial engine used as expander, and finally, (v) a volumetric gear pump controlled by an inverter that supplies the organic fluid over the ORC system position under the liquid receiver (tank), realizing a column of water about $1 \mathrm{~m}$ high.

\subsection{Computational Grid and Dynamic Mesh Approach}

The numerical simulations and meshing phase are developed by means of the software Pumplinx 4.6.4 by Simerics Inc. ${ }^{\circledR}$ (Bellevue, WA, USA). The virtual model depicted in Figure 1 is discretized by means of a Cartesian grid (binary-tree mesh type) for the stationary domains (such as piping and gear pump body) and a body-fitted curvilinear mesh type for the rotary domains (such as the gear pump wheels). Figure 2 reports two mesh details of the stationary components: the outlet section of the regenerator and the inlet section of the CFM. The stationary mesh is composed of about 3 million elements. Finer grid elements are adopted at the variation of the passage area, especially in the proximity of the inlet and exit valves. Due to these geometric features, the element size of the mesh is adapted according to the passage area. In particular, in each section, an element number in the range of 20-30 was adopted along the pipe diameter. A detailed description of the element size adopted for the gap discretization is reported in the following section.

The dynamic mesh approach was adopted with the aim of analyzing the transient phenomenon generated by the gear pump operation. For this reason, particular attention was given to the mesh generation of this component. The internal volume of the gear pump has been discretized through a structured mesh able to account for the wheel rotation and engagement over the transient analysis. The rotation and engagement processes determine the modification of the internal shape of the computational domain at each time-step. The computational mesh of this section consists of about 300,000 hexahedral elements, which have been associated with a deformation algorithm able to simulate the rotation of the wheels and their engagement. Figure 3 shows four successive instants related to the rotation and engaging of the gear pump wheels. It can be seen how the grid elements (in the vane) are able to adapt and change their shape, to accommodate the presence of the tooth of the opposite wheel. The rotating domain is connected to the suction and discharge ports through sliding interfaces able to couple the stationary and rotating domains. The subdivision between stationary and rotating domains inside the gear pump is depicted in Figure 4. The suction and delivery ports of the gear pump are connected via sliding interfaces to the rotating domain.

The computational mesh, composed of about 3 million elements and depicted in Figures 2-4, is the result of a mesh sensitivity analysis (from 2 million to 4 million elements) that was carried out with the aim of validating the numerical results against the experimental data. A detailed comparison and quantification of the deviation between the numerical results and the actual ORC operation is reported in the following sections. 


\subsection{Gear Pump Virtual Model and Main Features}

The pump displacement is equal to $7.5 \times 10^{-6} \mathrm{~m}^{3}$. The volumetric flow rate provided by the gear pump can be adjusted according to the ORC requirements by varying the rotational velocity. This ideal displacement is affected by the unavoidable leakages that characterize these machines. By means of the present simulation strategy, it is possible to include in the fluid dynamic analysis all the leakages through the gaps: between the wheels and the pump casing (i.e., tooth flank-pump casing sides and tooth head-pump casing periphery) and the engagement region.
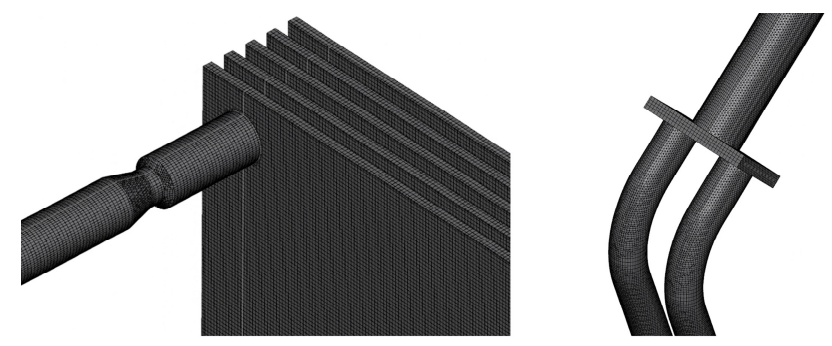

Figure 2. The unstructured Cartesian grid on stationary components: the outlet section of the regenerator and the CFM inlet section.

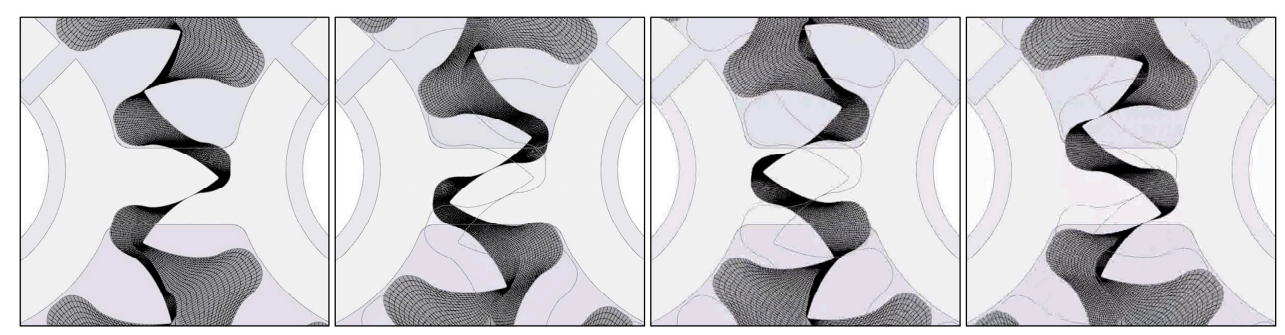

Figure 3. Subsequent instants of engagement process discretized by means of a dynamic mesh strategy.
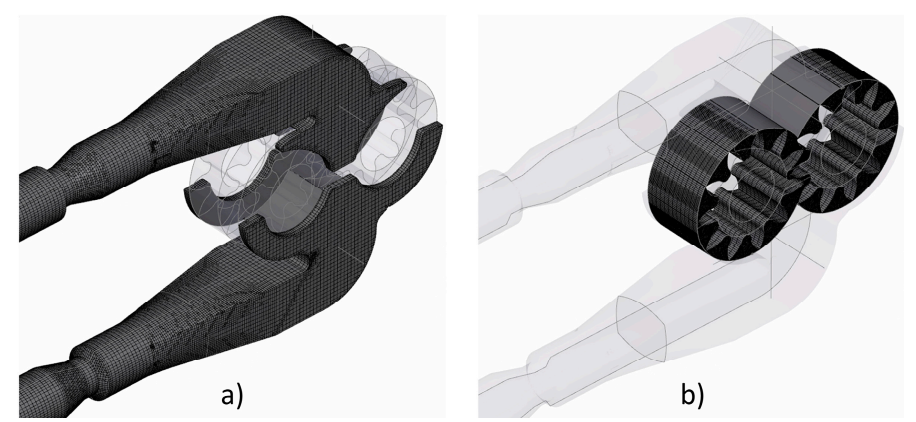

Figure 4. The computational mesh of the gear pump: (a) suction and delivery ports, and (b) rotating wheels equipped with hexahedral mesh elements.

The liquid flows through these gaps according to the pressure gradient, from the discharge port to the suction port determining a volumetric efficiency lower than one. This phenomenon characterizes all rotating volumetric machines and is one of the main points of interest for the fluid dynamics simulation of this type of machine. In fact, an ideal positive displacement machine has to perfectly seal the suction port with respect to the discharge port, but the manufacturing processes and the necessity to reduce the friction between the moving and fixed parts determine the axial and radial gaps.

The axial gaps are due to the axial clearance that exists between the wheels and the pump case. In the present analysis, the axial gap is equal to $20 \mu \mathrm{m}$ and contributes to a decrease in the volumetric efficiency of the gear pump. In Figure $5 a$, the computational grid in the axial gaps is reported. It is 
realized by means of five layers of hexahedral elements and coupled with the rotating domain through a sling interface.

In a different way of the axial gaps, the clearance between the tooth head and the pump casing is a function of the angular position of the wheel and they vary in the range of 50-100 $\mu \mathrm{m}$. Each angular position of the wheel is characterized by a different distance between the tooth head and the pump casing due to the eccentric position of the wheel. The eccentric position is related to the unbalanced pressure forces between the wheel region facing the delivery port (high pressure) and the wheel region facing the suction port (low pressure). The fluid pressure at the port acts on the overlocked wheel portion, generating a certain load. The fluid pressure at the delivery port is higher than the pressure value at the suction port; for this reason, the wheel is not concentric with respect to the pump casing but is located in an eccentric position responsible for the lower values for the tooth-head gap in the proximity of the suction port.

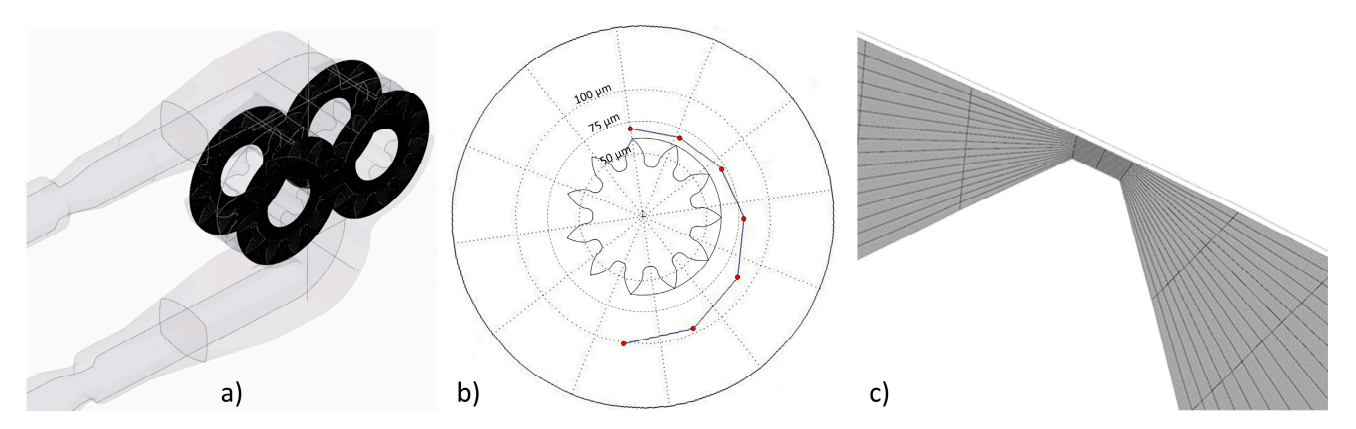

Figure 5. Particular domain discretization in correspondence of the gaps: (a) between the tooth flank and pump casing, (b) between the tooth head and the pump casing as a function of the angular position, and (c) computational mesh in the tooth head-case gap.

In Figure $5 b$ the magnitude of the gaps is reported by means of a polar diagram, in which the delivery section is in the lower part while the suction section is in the upper part. They vary (in particular, increase) starting from about $70 \mu \mathrm{m}$ up to $100 \mu \mathrm{m}$.

In the tooth-head gap, thanks to the deformation strategy adopted for the computational mesh, the number of elements used to discretize that region is identical to the number of elements used to discretize the vane volume. In particular, 16 elements were adopted for the radial discretization of the gear pump vane, that allows a proper resolution of the flow field. Figure $5 \mathrm{c}$ reports the computational mesh in correspondence of the gap between the tooth head and the pump case and shows the grid refinement in this particular region.

The last contribution to the reduction of volumetric efficiency is due to the engaging process. In the engaging region, when two teeth pairs come into contact, a trapped volume could arise and, in the case of the wrong design, it can experience a progressive volume reduction, leading to a sudden change in pressure [11]. To avoid this, the trapped volume is always connected with the high- or low-pressure chamber. This role is performed by purpose-built pockets in the lateral side of the pump casing, named relief grooves, whose dimensions are very important to the resulting dynamic behavior. The shape and position of this relief groove are depicted in Figure 6. The radial width of the relief groove must be balanced in order to (i) avoid the pressure rise caused by the trapped volume and (ii) limit the flow escaping from the delivery (high pressure) to the suction (low pressure) ports. As can be seen from the two successive instants shown in Figure 6, the relief groove is firstly connected to the suction (upper) and discharge (lower) ports (see Figure 6a) and then sealed by the contact between the two tooth pairs in contact (see Figure 6b). In the latter position, the teeth in contact do not allow fluid flow from the delivery to the suction port.

In addition to the negative contribution to the volumetric efficiency, the backflow from the discharge to the suction port through the relief groove also determines pressure pulsations that could affect the flow field at the suction ports of the gear pump. In this region, a high-pressure jet of fluid 
coming from the groove experiences a sudden pressure drop increasing the pressure variation and the cavitation effects. This phenomenon, strongly related to the transient phenomena experienced by the gear pump, will be considered in the subsequent analysis of the results, with particular attention to the repercussions of this effect on cavitation and on the variation in pressure field induced by the CFM, which is installed upstream of (but close to) the gear pump.
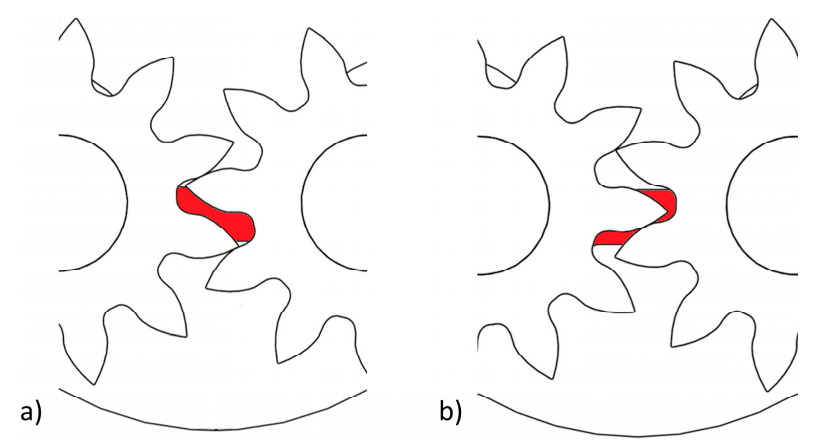

Figure 6. Engaging process compared to the relief groove shape: (a) the two pairs of teeth do not seal the relief groove with respect to the suction/discharge ports and (b) the teeth contact isolates the relief groove and seals the suction/discharge ports.

\subsection{Operating Conditions}

The refrigerant (in the liquid phase) considered in the present analysis is the $\mathrm{R} 134 \mathrm{a}\left(\mathrm{F}_{3} \mathrm{C}-\mathrm{CH}_{2}-\mathrm{F}\right)$. Over the modeled flow path, the liquid refrigerant experience the pressure rise provided by the gear pump. The aim of the present analysis is to show dynamic phenomena such as pressure pulsation and cavitation, and for this reason, the present analysis is carried out avoiding the thermal power exchanged at the regenerator and the heat dissipated with the environment.

Dealing with dynamic analysis, the boundary conditions of the present investigation are averaged values according to the gear pump rotation. The transient analysis is carried out adopting a time-step adequate to solve the $0.5^{\circ}$ rotation of the gear wheels.

The liquid receiver (tank) is considered pressurized at a fixed pressure level of $601,325 \mathrm{~Pa}$, while at the evaporator inlet, the imposed pressure is 1,601,325 Pa. These pressure boundary conditions are in line with the operating point reported in [21], and are bounded by the heat source and sink constituted of water, having a temperature in the range $18-25^{\circ} \mathrm{C}$ at the condenser and $60-90^{\circ} \mathrm{C}$ at the evaporator.

According to the pressure boundary condition, the gear pump rotational speed is adjusted (in the range from $450 \mathrm{rpm}$ to $475 \mathrm{rpm}$ ) in order to guarantee a mass flow rate of about $0.1 \mathrm{~kg} / \mathrm{s}$, which is considered the target value for the present analysis. Since the pump operation is affected by the leakages and the cavitation phenomena, the target mass flow rate is guaranteed with different rotation speed related to the sub-cooling degree that occurs at the condenser. The sub-cooling degree determines the liquid saturation pressure, which represents the most important values for the cavitation phenomenon. Starting from a reference condition (which corresponds to $450 \mathrm{rpm}$, liquid temperature of $293 \mathrm{~K}$ and saturation pressure of $569,060 \mathrm{~Pa}$ ), two additional operating points have been simulated according to the working parameter of the ORC control system (variation of the liquid temperature and pump rotational speed). Details about these two additional analyses will be reported later.

As described above, the suction section of the pump is affected by high-speed gradients of the fluid velocity due to the simultaneous presence of (i) wheel rotation and (i) backflow through the relief groove from the engaging region. These phenomena, associated with the thermodynamic condition of the liquid phase at the pump inlet (close to the saturated condition), and pressure losses introduced by the piping and fittings (pipes, valves, CFM, and bends) make the cavitation phenomenon one of the main issues of the present application (gear pump in a micro-ORC system). 


\subsection{Model Setup and Validation}

With reference to the previous description, all the numerical simulations were carried out by imposing a constant static pressure at the inlet $(601,325 \mathrm{~Pa})$ and at the outlet $(1,601,325 \mathrm{~Pa})$ sections of the virtual model depicted in Figure 1. For turbulence modeling, the $k-\varepsilon$ turbulence model was adopted. A constant liquid density $\left(1226 \mathrm{~kg} / \mathrm{m}^{3}\right)$ and viscosity $\left(2.02 \times 10^{-4} \mathrm{~Pa} \mathrm{~s}\right)$ values are also specified for each operating condition. The cavitation phenomenon is modeled by means of the equilibrium dissolve gas model implemented in Pumplinx 4.6.4 [24].

As mentioned, the numerical model was validated against experimental data taken from [21]. The sensitivity analysis of the computational mesh was carried out with the aim of reproducing the experimental results and, at the same time, limiting the computational effort. Figure 7 reports the comparison between the mass flow rate $m$ obtained from the experimental data and from the numerical solutions with respect to the gear pump rotational speed $\omega$. The mass flow rate values are taken as an averaged value of the instantaneous mass flow rate provided by the pump. The data are in reasonable agreement (error bars equal to 10\%), especially in the range from $425 \mathrm{rpm}$ to $525 \mathrm{rpm}$. For cases with lower values of rotational speed, the presence of a lubricant oil (in a fraction between $3 \%$ and $6 \%$, see [21]) allows the sealing process in the flank and radial gaps and, for this reason, the mass flow rate looks greater than the values obtained in numerical simulations.

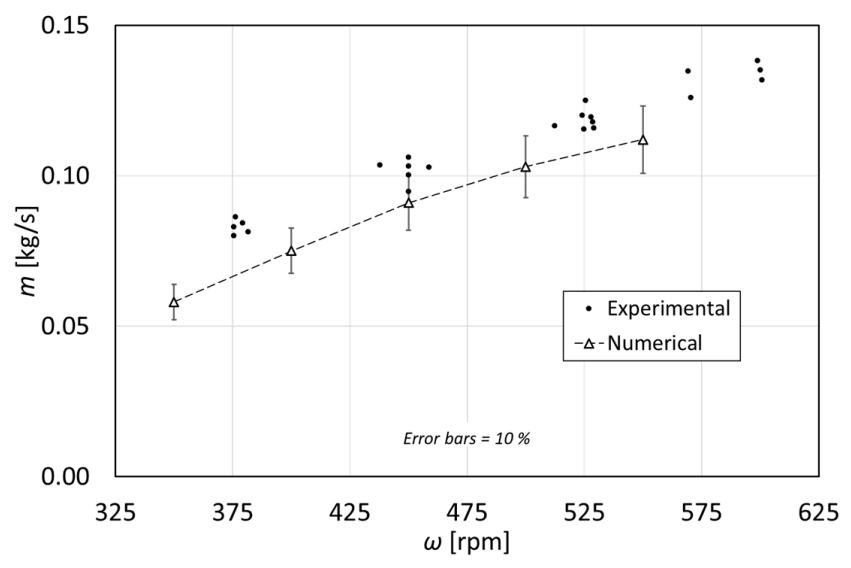

Figure 7. Model validation: comparison between the experimental data (taken from Bianchi et al. [21]) and the numerical results.

\section{Results: Pump Operation}

In this section, the results of the transient fluid dynamic analysis carried out with the dynamic mesh strategy will be reported. The results have to be referred to the angular position of the wheel. Each wheel is composed of 11 teeth, and for this reason, each plot will refer to a $32.7^{\circ}$ rotation step. The reference of the angular position $\alpha$ (which corresponds to the origin of each plot) will be superimposed on each graph.

\subsection{Mass Flow Rate and Velocity Field}

The simulation strategy employed allows us to know the flow rate supplied by the positive displacement machine according to the fluid characteristics, rotational speed and operating conditions of the plant (pressure difference). The trend reported in Figure 8 shows the mass flow rate at the outlet section of the considered ORC virtual model (evaporator inlet). The mass flow is not constant but the trend follows the operation of the gear pump, which releases a certain volume of fluid in relation to its angular position. The peak of the mass flow rate corresponds to the vane released at the pump outlet section. Thanks to the time resolution of the transient simulation, it is possible to calculate, with a good approximation, the average flow rate processed by the gear pump during its rotation. For the actual rotational speed (450 rpm), the average value of the mass flow rate is equal to $0.091 \mathrm{~kg} / \mathrm{s}$, which 
is the result of the contemporary presence of the subsequent vane released at the discharge section and leakage driven by the pressure difference from the outlet to the suction port.

The average value of mass flow rate is affected by the leakages that occur in the pump region, reported and described in the previous section. Fluid dynamic representations of the flow leakages are reported in Figure 9. From the high-pressure section (pump discharge section), the liquid refrigerant flows through the axial gap (Figure 9a) and through the tooth-gap (Figure 9b), reducing the volumetric efficiency of the gear pump. Therefore, these leakages reduce the net flow rate processed by the pump measured at the outlet section since a small part of the fluid already processed by the wheels returns from the discharge to the suction port.

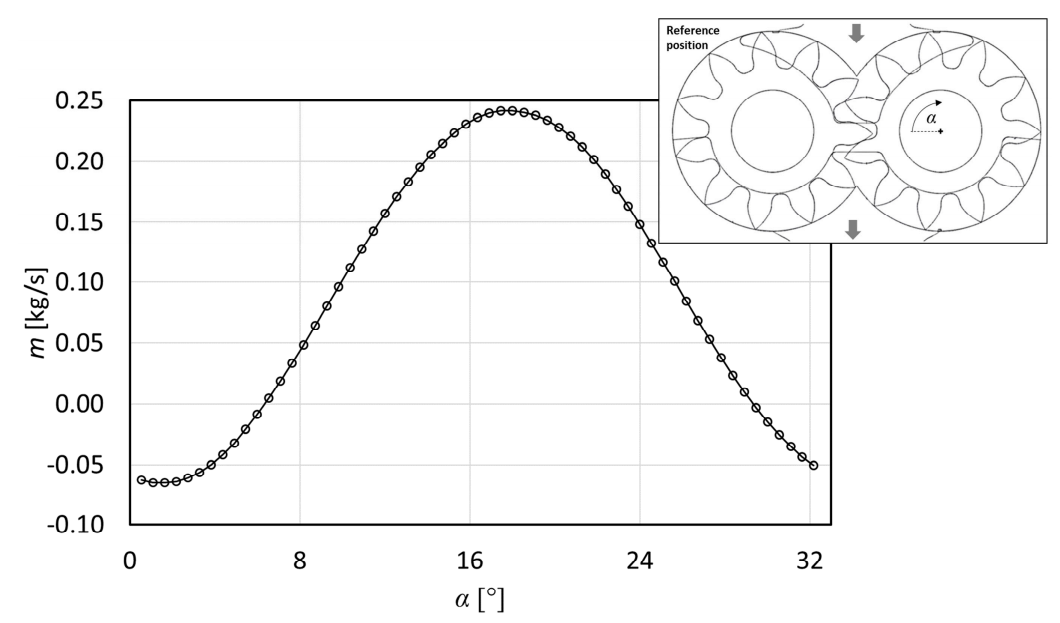

Figure 8. Mass flow rate trend according to the angular position of the wheel (see reference position).
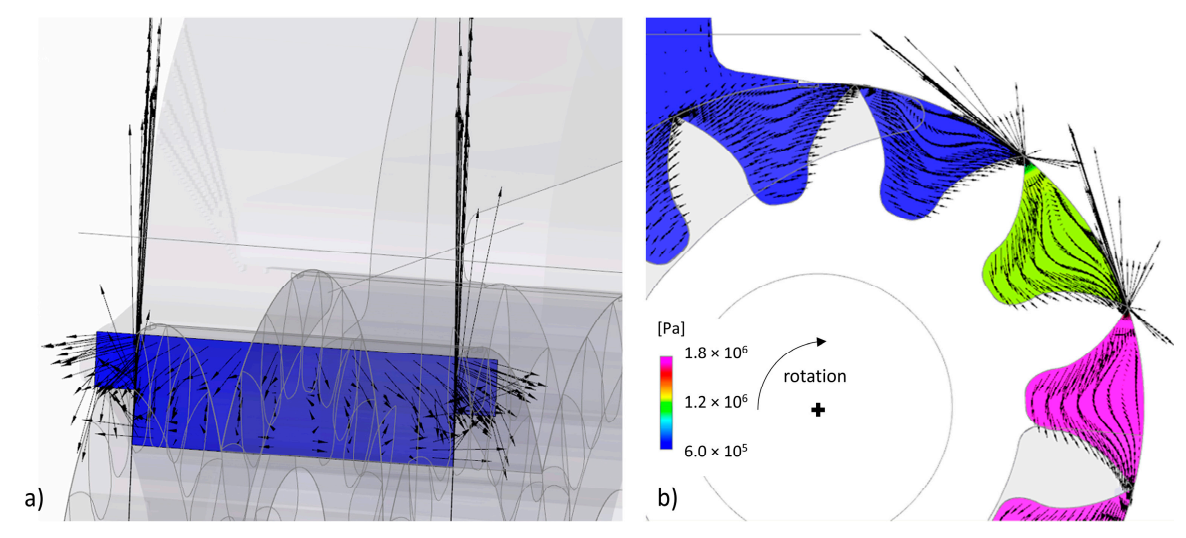

Figure 9. Velocity vector in the gaps: (a) tooth-flank gap and (b) tooth-head gap.

In Figure 9b, two families of vectors can be seen: the vectors with the same direction of wheel rotation versus vectors with opposite directions. The agreed vectors are those that represent the fluid moving from the suction to the delivery thanks to the sealing process provided by the teeth and thanks to the no-slip condition imposed on the wheel surfaces, while the discordant vectors represent the fluid that, driven by the pressure difference, flows from the delivery to the suction ports through the radial clearance (tooth-head gaps).

\subsection{Pressure Field and Pulsations}

In the present section, the pressure pulsations at the gear pump inlet and outlet ports are reported. The pressure pulsations were detected upstream and downstream of the gear pump thanks to the use of two virtual probes facing the suction and discharge ports. The positions of the two measurement points are shown in Figure 10. In these ports, the pump operation, characterized by the teeth passages 
in front of the ports, generates high turbulence and mixing. At the inlet section $\left(p_{\mathrm{IN}}\right)$, the fluid trapped in the meshing region determines the backflow of fluid, which is drawn from the delivery and released towards the suction port. According to the angular position of the wheel, the pressure reduction experienced by the pressure probe at the inlet section is due to the vane-filling process that occurs for the vane that finishes the engagement process, generating a sudden increment of the available volume at the suction section. At the outlet section $\left(p_{\mathrm{OUT}}\right)$, the pulsations are mainly due to the delivery of the trapped volume between two consecutive teeth. The results of all these phenomena on the suction and discharge ports are shown in Figure 10. Figure 10 also shows the sealing process and the consequent pressure field referred to a mid-plane of the tooth width. The pressure increment involves two consecutive vanes in the upper part of the pump (close to the suction section), according to the gaps in radial distribution shown in Figure $5 b$.

From the mass flow trend reported in Figure 8, it can be seen that, for a certain angular position range of $10^{\circ}$ wide, a reverse flow condition characterizes the ORC system. Based on these findings, in Figure 11 two instants have been reported, representative of the flow conditions at $0^{\circ}$ and $16.5^{\circ}$. These two conditions correspond to the instant at which the flow is reversed $\left(0^{\circ}\right)$ and the time of maximum flow $\left(16.5^{\circ}\right)$. The flow field is taken according to the section plane depicted in the figure located in the discharge section of the regenerator. The pressure pulsation implies that, for a certain interval, the flow moves from the outlet section towards the regenerator driven by the pressure difference. Figure 11a shows that the discharge pressure is greater than that generated by the pump, determining the reverse flow. By contrast, in Figure 11b, the pressurization generated by the gear pump is greater than what exists at the outlet, and the fluid is supplied to the regenerator outlet.

The pressure depicted in Figure 11 also highlights the pressure losses due to fittings and valves. The pressure loss reaches $2000 \mathrm{~Pa}$, generated by the restriction in the flow passage area corresponding to the valve that divides the regenerator (highlighted in the sketch) and the evaporator (not considered in the present analysis) units. The flow passage section varies according to the valve and fitting internal geometries responsible for the localized pressure drop.
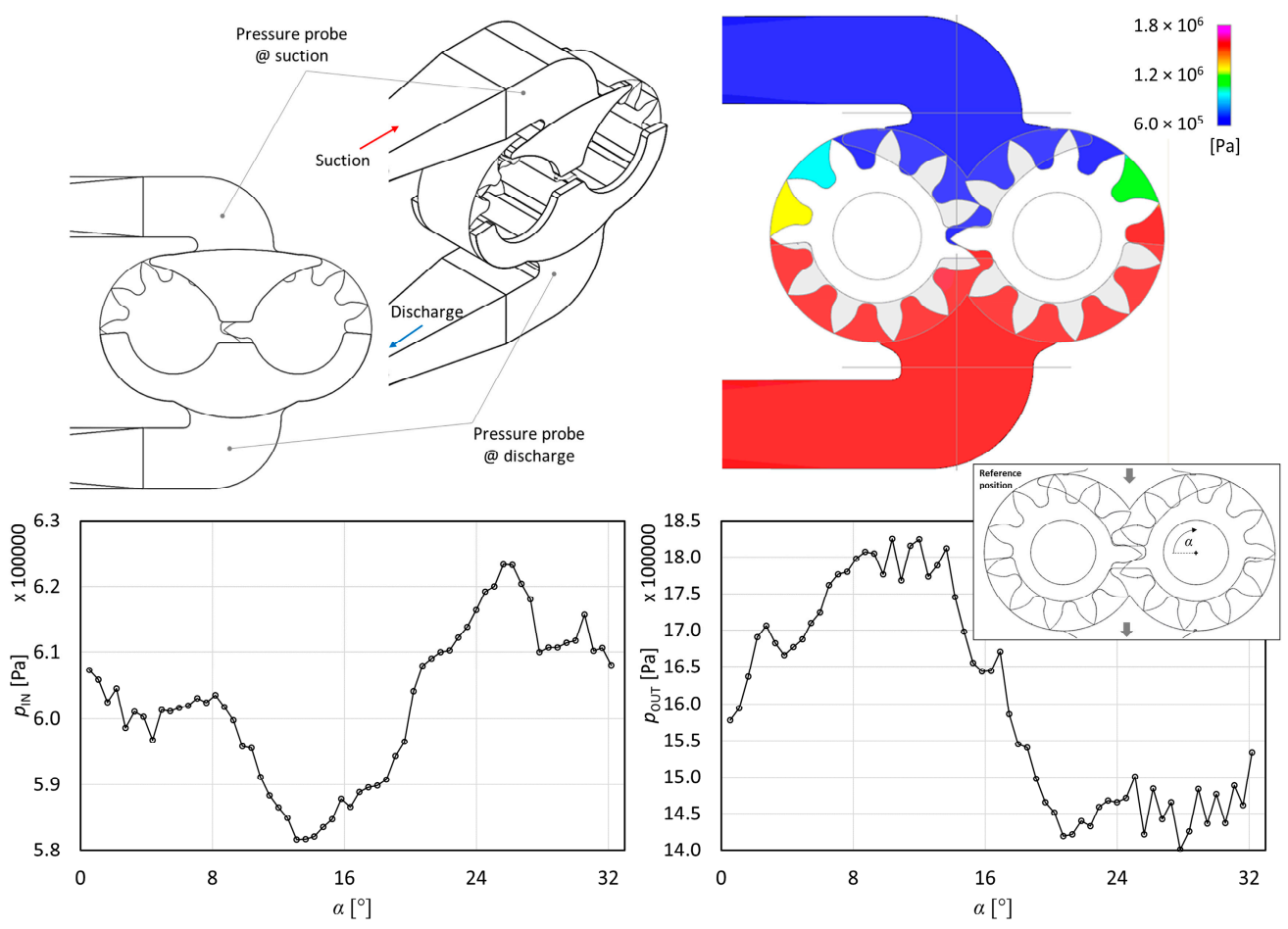

Figure 10. Pressure pulsation at the suction and discharge ports of the gear pumps (see reference position). The pressure field is referred to as the mid-plane of the tooth width. 


\section{Results: Response of the Cycle}

\subsection{Dynamic Effects on Coriolis Flow Meter}

The pressure pulsation generated by the pump operation influences the entire ORC system. The CFM operating principle is based on the Coriolis force. The Coriolis force is due to the rotation. Each CFM includes one or more measuring tubes, which are equipped with an exciter able to generate a controlled oscillation. As soon as the fluid begins to flow inside the measuring tube, another oscillatory motion is imposed on the same tube due to the fluid inertia. Two sensors detect this change in the tube oscillation amplitude, frequency and phase difference. This difference is a direct measure of the mass flow rate. By taking into consideration the operating principle of a CFM, it is clear how a pressure pulsation may alter the measurement, introducing vibrations and oscillation not related to the mass flow rate. Based on these considerations, thanks to the transient analysis and the dynamic mesh approach, the pressure pulsations to which the CFM is subjected were monitored.

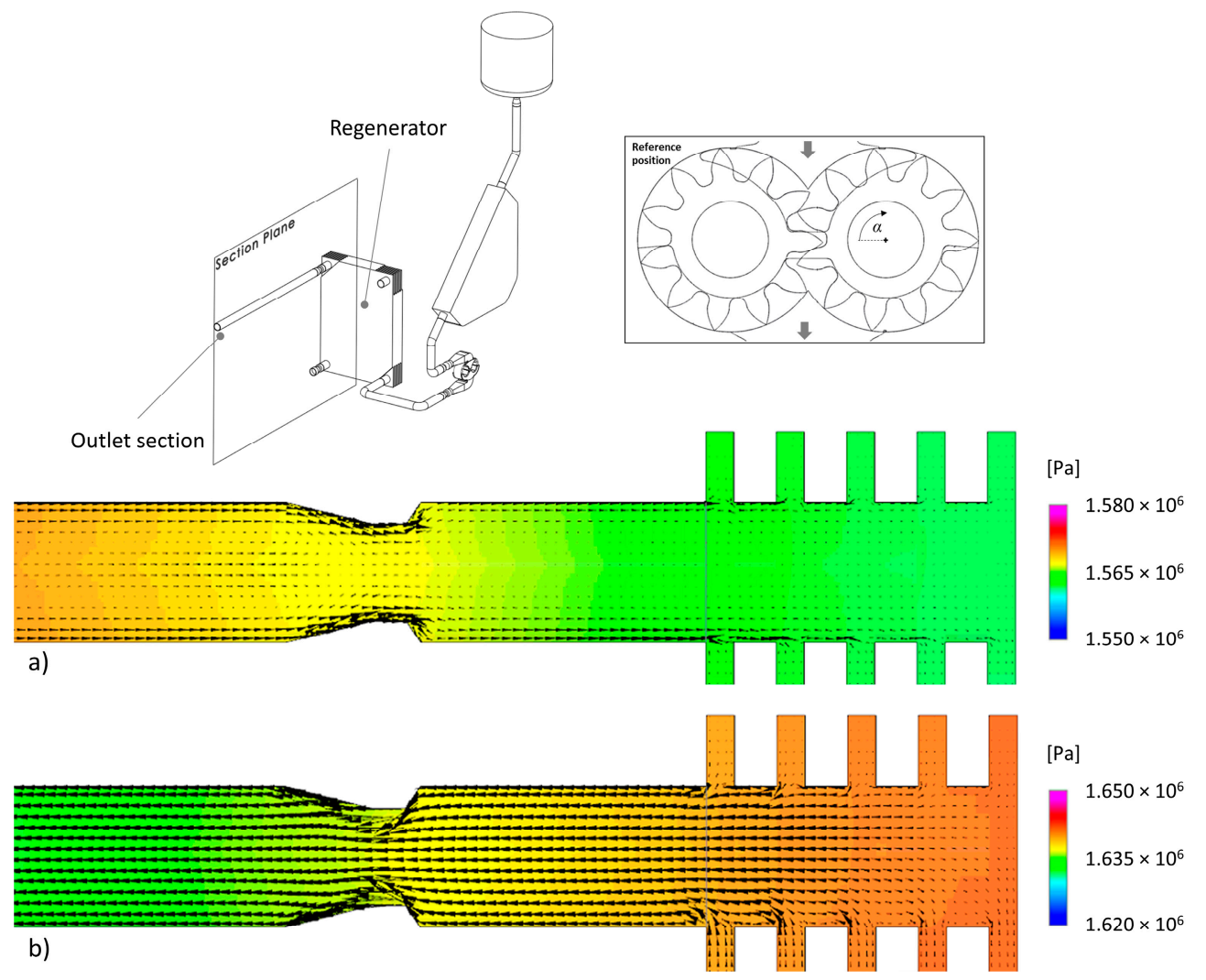

Figure 11. Pressure field and velocity vector at the regenerator outlet section at (a) $0^{\circ}$ and (b) $16.5^{\circ}$ (according to the reference position).

As described and reported in Figure 1, in the present ORC system, the CFM is installed before the gear pump, in line with the aim of reducing the effects due to the pressure pulsation generated by the gear pump. A different installation (CFM positioned after the gear pump) could determine higher values of pressure pulsation and, in turn, more detrimental effects due to flow disturbances on the CFM measuring performance. In many cases, the manufacturer of the flow meter indicates the proper distance between other devices, fittings and bend and the flow meter, but, considering the dynamic effects of positive displacement machine, the pressure pulsation involves the overall systems, implying that particular attention must be paid to the flow meter usage. The aim of this data post-processing is to show how, instead of proper installation, the interaction between two components could determine additional issues in the ORC control system. 
The present analysis reports the pressure pulsation due to the gear pump generation without considering the damping effects provided by the frame that equipped the ORC systems (see, for example, the ORC skid in [21]). Therefore, the amplitude of the pulsations is intended as the greatest possible in terms of pressure and force. Also, the vibrational response of the structure is not considered in this work. Therefore, the analysis is intended to show the capabilities of the dynamic simulation to detect important features related to the system control beyond the mostly know results related to the flow field and machine performance. The inertia of fluid, together with the geometric features and pump operation work at the same time, and drive the interaction between two or more components. This type of analysis makes it possible to extract general guidelines for reducing the negative effects of pump operation on the CFM measurement performance.

Figure 12 shows the pressure trends according to the wheel angular position monitored upstream $\left(p_{\text {IN,CFM }}\right)$ and downstream ( $\left.p_{\text {OUT,CFM }}\right)$ of the mass flow meter. As can be seen from the pressure trends, the CFM is affected by the pump operation even if it is positioned upstream with respect to the gear pump. Pressure pulsations generate pressure forces that affect the CFM body, as reported in Figure 12. The magnitude of the force $\left(F_{\mathrm{CFM}}\right)$ is lower than $3 \mathrm{~N}$ but is variable according to the angular position of the wheel. This effect could generate some inaccuracies and disturbances during the mass flow rate measuring process.
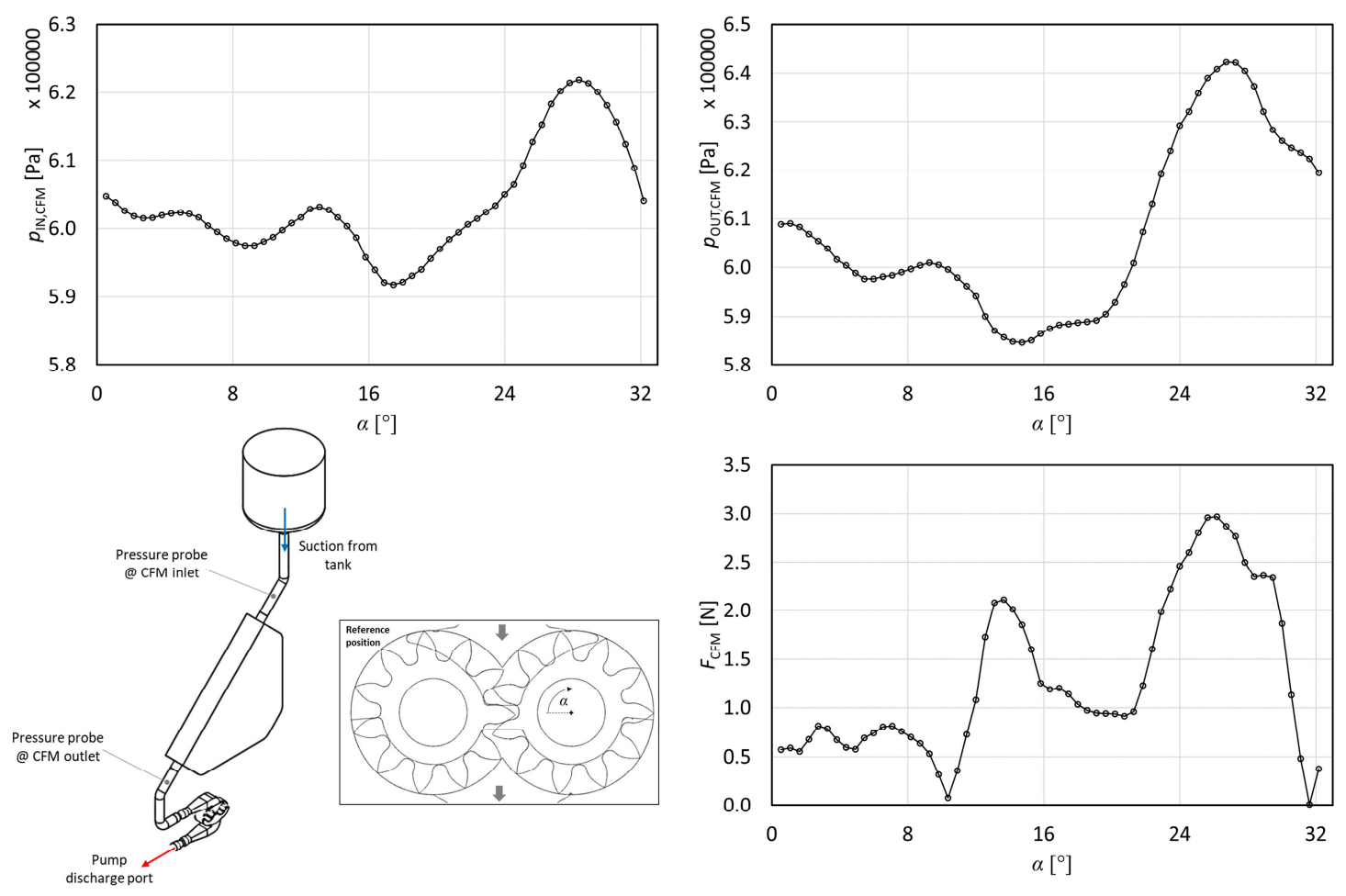

Figure 12. Pressure pulsation at the inlet and outlet sections of the CFM and the force trends according to the angular position of the gear pump wheel (see reference position).

In addition to the magnitude, the frequency of this pressure pulsation could also affect the performance of the CFM. Figure 13 shows the Fast Fourier Transformation (FFT) of the force signal reported in Figure 12. Each harmonic is reported according to its frequency, which corresponds to a multiple of the first harmonic obtained by considering the number of teeth (11) and the rotational velocity (450 rpm) adopted in the present analysis. 


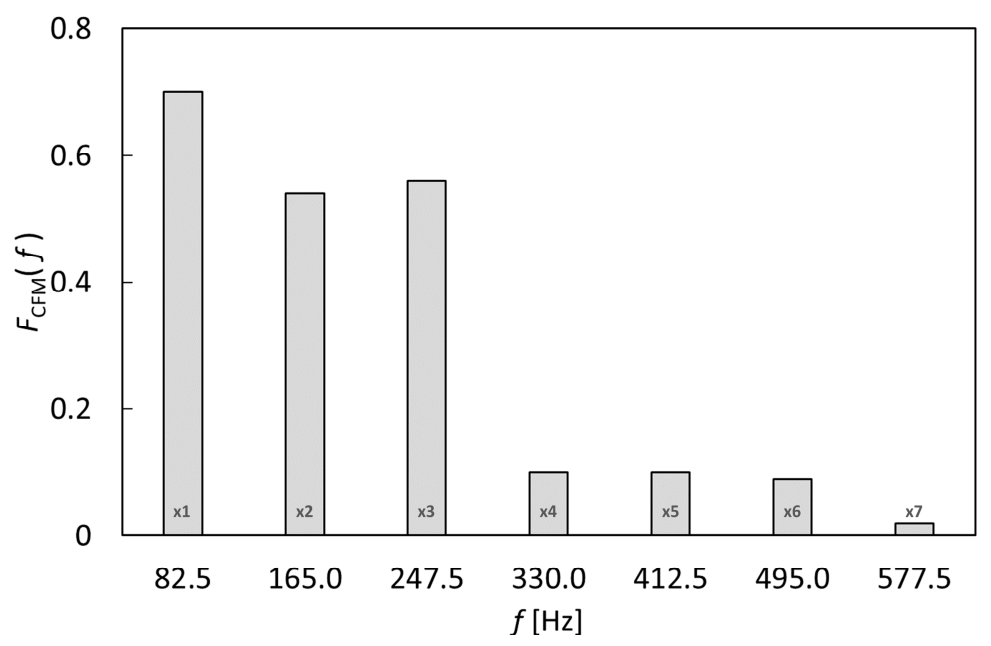

Figure 13. Harmonics magnitude and frequencies obtained by FFT of the force signal.

The magnitude of each harmonic is mainly based on the interaction between the wheels, relief groove located in the meshing region and the cavitation phenomenon. The FFT analysis permits the detection of possible dangerous interactions between the gear pump and the CFM operation. The presence of the cavitation phenomenon could generate a specific harmonic that may influence the CFM measurement performance. As reported in Figure 13, the third harmonic (corresponding to $247.5 \mathrm{~Hz}$ ) is higher than the second one (corresponding to $165.0 \mathrm{~Hz}$ ), representing a different excitation regime with respect to the natural one, which is easily determined by knowing the rotational speed and the number of teeth. This means that for certain operating conditions (depending on the rotational velocity and saturation pressure) the frequency of the flow disturbance may affect the CFM operation in terms of accuracy and stability [13,14]. Even if modern CFM adopts the high oscillation frequency of the measuring tubes to ensure that the correct operation of the measuring system is not influenced by pipe vibrations, analysis of the installation issues is preferable. In fact, the flow disturbance, as well as other noise (e.g., variable drive), could upset the precise measurement of a Coriolis sensor. Therefore, even with the aforementioned limitations involved in the present approach, the dynamic simulation allows for the analysis of the interaction between a single component (e.g., gear pump) and a measurement device (e.g., Coriolis flow meter). From the CFD results, it is possible to highlight several guidelines for reducing the aforementioned drawbacks:

- check the resonance frequency of the CFM installed against the pump operating range, including off-design conditions;

- cavitation phenomena could change the amplitude of the harmonics, determining different disturbance on the CFM operation according to the ORC operating point. For this reason, a proper design of the gear pump capacity could reduce the cavitation issues. Higher pump capacity allows for a reduction in the rotational velocity, limiting the cavitation issues and the corresponding high-frequency phenomenon (explained in detail in the following section);

- looking at the measurement performance, a stable pump operation can be assumed as a sort of offset with respect to the ideal measurement condition. When fluid dynamic effects (such as cavitation) occur, the measurement performance could fall down, reducing the chances to correct the measurement after the calibration process due to the non-linear interaction between the gear pump and the CFM;

- the use of check valves could reduce the backflow, generating a more stable operating condition of the gear pump. 


\subsection{Cavitation and Its Effects on the Control System and ORC Operating Point}

The possibility of simulating the interaction of several components within an ORC cycle allows for the assessment of the control system performance and strategy, in particular: (i) characteristic time, (ii) priority and (iii) devices to be preserved and/or monitored for improving the reliability of the system. In fact, any control system is characterized by its own characteristic time, which is usually given by the component (active device or sensors), which shows the longest characteristic time coupled with the calculation and post-processing time of the data coming from the field. The decisions and actions taken by the control system must also meet some priority criteria (activation and/or control of devices) and satisfy certain criteria (boundaries) beyond which it is not possible to operate the system. In light of these considerations, the capability to simulate the interaction between two or more components represents valid support in this sense. A demonstration of such a powerful contribution given by the CFD calculation of the entire ORC system has already been reported in the literature [22,23], and a similar strategy is applied in this work for analyzing the gear pump operation.

Figure 14 shows an example of a control strategy that usually reacts to a sudden increase in the energy exchanged by the refrigerant fluid in the evaporator. This situation is quite common in ORC cycles, which are usually used to recover energy from energy waste, which is subject to unpredictable variations.

Following the diagram of Figure 14, starting from a steady-state operating condition, due to the greater energy exchanged in the evaporator, the refrigerant reaches a higher temperature upstream and downstream of the expander and, consequently, at the inlet of the condenser, the fluid will be warmer than the previous stationary condition. At the condenser, the thermal inertia of the system does not allow for an instantaneous reaction, generating an outlet liquid phase refrigerant with a lower degree of sub-cooling. For the liquid phase, a higher condenser outlet temperature implies higher saturation pressure and, consequently, greater cavitation effects.

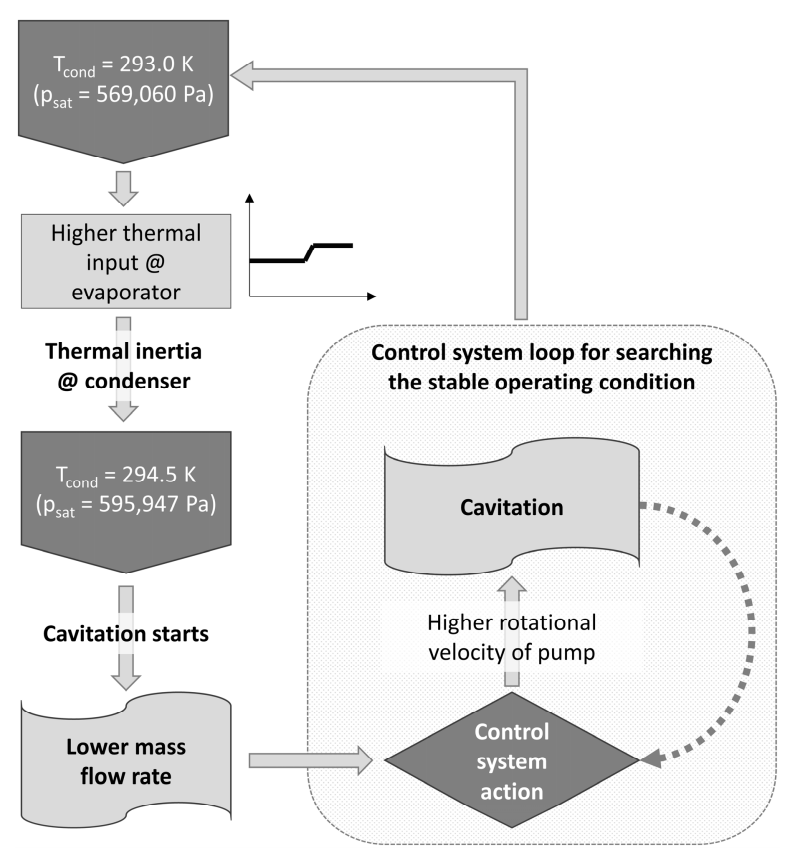

Figure 14. Logic diagram of the control system considering the local fluid dynamic behavior.

The phenomenon of cavitation (as described above) is closely related to the rotation speed of the pump, which is the parameter that the control system changes to adjust the flow, which is inevitably decreased as a result of the greater cavitation phenomenon. The control system, therefore, requires a greater rotation speed to restore the required flow rate searching the new operating point, for which a greater condenser cooling capacity will be required. Table 1 collects the conditions generated by the 
control system actions, and for which the numerical simulations are carried out. Pressure boundary conditions are the same of the previous analysis (corresponding to the operating point A of Table 1), only the liquid temperature, saturation pressure, and gear pump rotational speed are varied according to the previous description.

Figure 15 shows the contour plots of the gas fraction inside the gear pump, corresponding to the mid-plane of the tooth width for three different operating conditions: (i) the stationary operating points where the previous analyses are carried out (liquid temperature in the tank of $293.0 \mathrm{~K}$, which corresponds to a saturation pressure of $569,000 \mathrm{~Pa}$ ) and a rotational velocity of $450 \mathrm{rpm}$, (ii) the operating condition due to the instantaneous increment of the outlet temperature at the condenser (liquid temperature in the tank of $294.5 \mathrm{~K}$, which corresponds to a saturation pressure of $596,000 \mathrm{~Pa}$ and a rotational velocity of $450 \mathrm{rpm}$, and, finally, (iii) the new operating conditions adjusted by the control system, with a rotating velocity equal to $475 \mathrm{rpm}$ for a liquid temperature of $294.5 \mathrm{~K}$. The quantification of the gas mass fraction allows for the evaluation of the contemporary effects of wheel motion (the rotational speed of the pump) and thermodynamic conditions (the saturation pressure of the tank). As described above, the contemporary effects of wheel rotation and temperature drop to generate a greater cavitation effect. From the control system point of view, the gear pump rotation is easy to measure and control in the opposite way of local temperature (or pressure), a result of the thermodynamic condition of the entire ORC cycle. For this reason, the analysis deals with the pump rotational speed as a driver of the cavitation phenomena reported in Figure 15. The similarities between the contour plots of Figure 15b,c are due to the value of the saturation pressure (and, thus, the temperature of the refrigerant in the tank), even if local phenomena (e.g., in the engagement region) are more intense in the worst case, characterized by the highest rotational speed (475 rpm).

Table 1. Operating conditions of the ORC system.

\begin{tabular}{cccc}
\hline Operating Point & Liquid Temperature [K] & Saturation Pressure [Pa] & Pump Rotational Speed [rpm] \\
\hline A & 293.0 & 569,060 & 450 \\
B & 294.5 & 595,947 & 450 \\
C & 294.5 & 595,947 & 475 \\
\hline
\end{tabular}

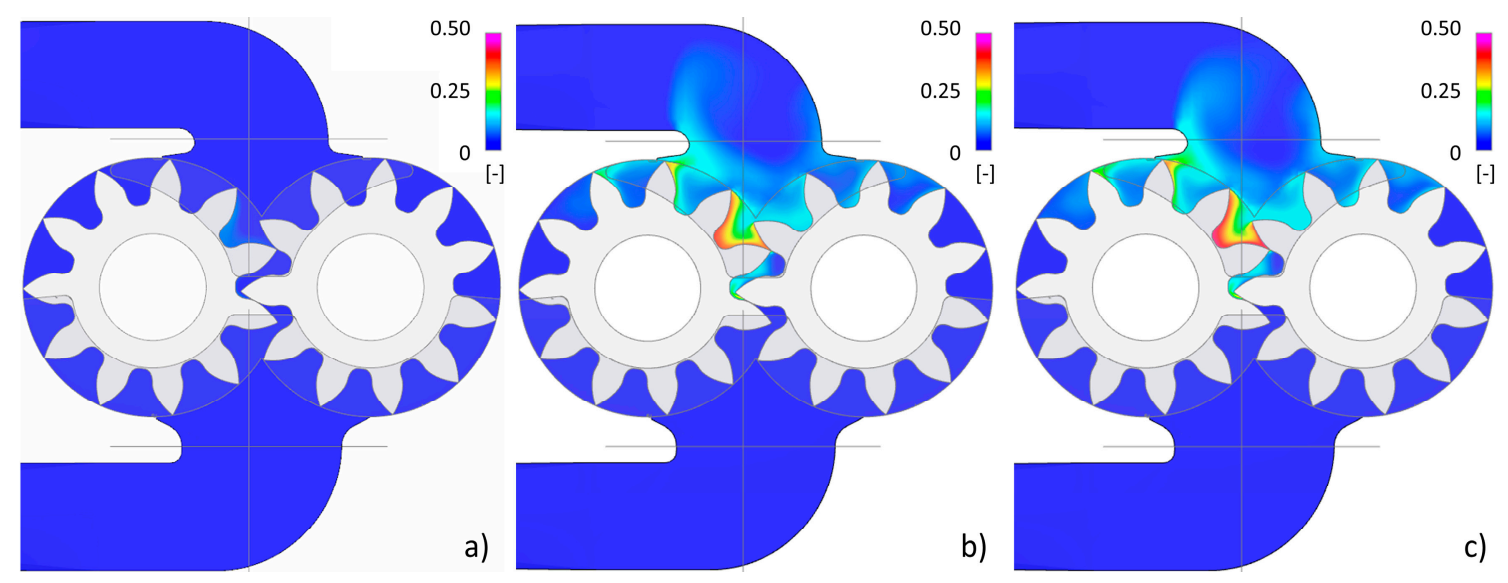

Figure 15. Contour plot of the gas mass fraction for a mid-plane of the tooth width according to three operating points: (a) condition A (450 rpm, $293.0 \mathrm{~K})$, (b) condition B (450 rpm, $294.5 \mathrm{~K})$ and (c) condition C (475 rpm, $294.5 \mathrm{~K})$.

From the three plots shown in Figure 15, it is clear that the analysis of the interaction between the components of an ORC circuit influences its operation and the actions of the control system. The cavitation shown in Figure 15 is closely related to both the thermodynamic conditions and the piping layout of the present ORC system. The cavitation phenomenon is determined by the wheel rotation and the pressure losses that the liquid refrigerant experiences when passing through the 
CMF and the suction port of the pump. For the stationary condition of Figure 15a, the gas fraction is reduced and confined only to the area downstream of the engaging region, while, when the sub-cooling decreases (see Figure 15b), the gas fraction involves a greater region at the pump suction port. From this condition, the mass flow rate decreases due to the reduced pump capacity that is affected by a certain amount of gas fraction at the suction port. The mass flow rate, processed by the pump according to the angular position of the gear wheel, is shown in Figure 16. As the operating conditions change, the flow rate processed changes, both in terms of the average value and the trend. In the stationary condition, the pump processes $0.091 \mathrm{~kg} / \mathrm{s}$. This average value decreases at the second operating point due to more severe cavitation conditions than previously. The average value of the mass flow rate, in this case, is equal to $0.082 \mathrm{~kg} / \mathrm{s}$ (which corresponds to a $10 \%$ lower value than previously). From this condition, the control system increases the pump rotational speed to $475 \mathrm{rpm}$, bringing the average flow rate value back to $0.091 \mathrm{~kg} / \mathrm{s}$.

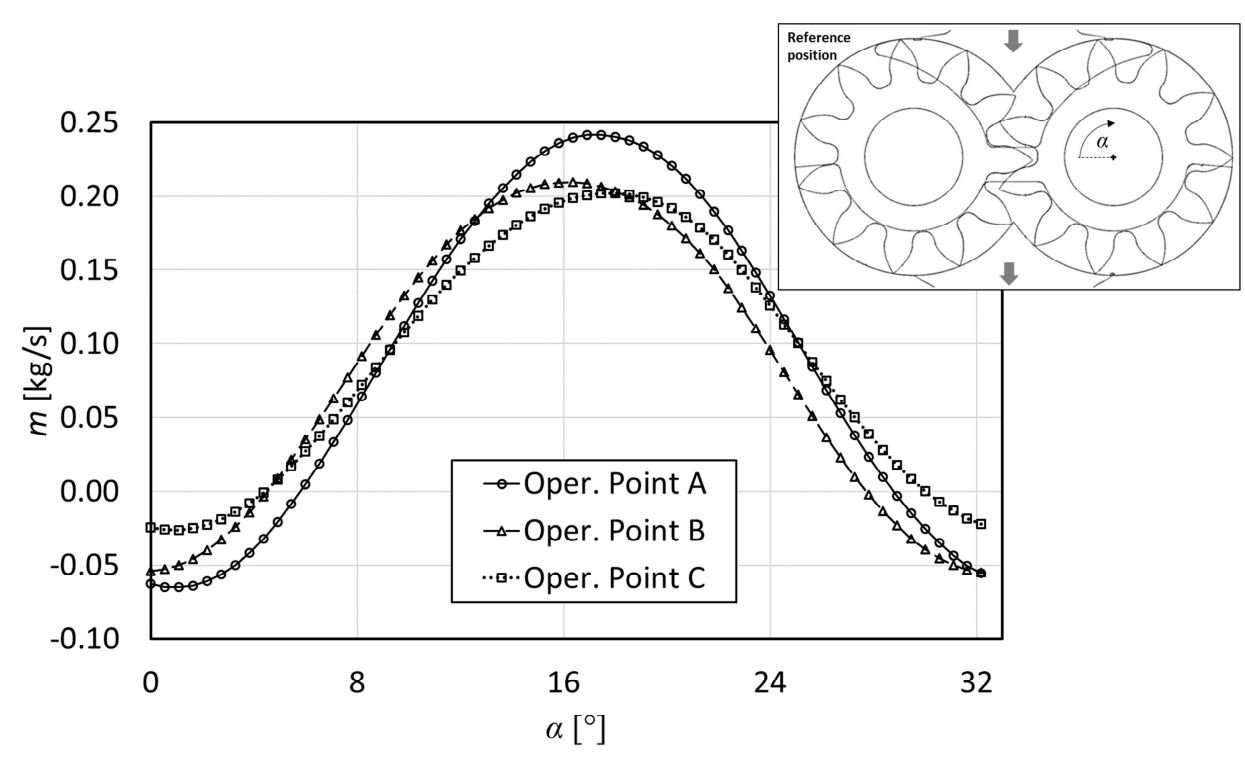

Figure 16. Mass flow rate trends according to the angular position of the wheel (see reference position) as a function of the three different operating conditions.

From the trends shown in Figure 16, it is clear that the new operating condition, even if characterized by an average flow rate identical to the starting regime condition, shows a different trend according to the angular position of the wheel. The presence of a greater gas fraction reduces the pulsation thanks to the greater compressibility of the liquid-gas mixture processed by the pump. Despite this smoother operating condition, cavitation could generate rapid erosion in some parts of the machine, especially at the axial gaps close to the suction port. In this region, the gas bubbles implode due to the localized increase in pressure.

\section{Conclusions}

In this paper, transient numerical simulations of a micro-ORC system branch have been carried out using a novel Whole Engine Model strategy. The aim of the present work was to analyze the fluid dynamic behavior of the gear pump operation on the system performance and control/measuring devices. The use of the dynamic model coupled with the dynamic mesh strategy allowed for the analysis of dynamic behavior such as pressure pulsation and cavitation phenomenon, related to the rotation and the engagement of gear pump wheels. With reference to the numerical results reported in this work, the main outcomes can be listed as follows:

- the operation of the gear pump in a micro-ORC system determines pressure pulsations that could affect the measurement systems and system performance; 
- pressure pulsations affect the operation of the Coriolis flow meter installed downstream of the liquid receiver and upstream of the gear pump. The pressure pulsation results in an excitation force that is variable according to the gear pump wheel position;

- the sub-cooling degree affects the gear pump operation. The pressure losses generated by the piping, fittings and suction port geometry, together with the dynamic effects of wheel rotation, determine a pressure drop responsible for the cavitation phenomenon;

- the cavitation phenomenon is promoted by the decreasing sub-cooling degree (which determines the saturation pressure of the liquid phase) and by the increasing pump rotational speed.

From the present analysis, it is clear that the actions of the control system affect the operation of every single component of an ORC system. The analyses have shown that certain transient conditions could determine several risks for the reliability and performance of components. Measuring performance can be preserved/improved by following specific guidelines, which involve both the design criteria of the devices and the control strategy of the ORC system. For example, the instantaneous variation of the evaporator thermal input could determine a cavitation phenomenon in the pump, which is subject to the action of the control system that requests more flow rate for increasing the energy exchanged at the evaporator. In this sense, numerical simulations of an actual installation may represent a valid support for better control and management of the systems, improving the performance, increasing the operating life, and reducing the risks of system damage.

Author Contributions: A.S. conceptualization and writing original draft; E.F. and S.R. data curation; M.P. methodology and supervision; N.C. writing—review \& editing.

Funding: This research was partially supported by the Italian Ministry of Economic Development within the framework of the Program Agreement MSE-CNR “Mi-cro co/tri generazione di Bioenergia Efficiente e Stabile (Mi-Best)".

Conflicts of Interest: The authors declare no conflict of interest.

\section{Nomenclature}

$\begin{array}{ll}F & \text { Force } \\ m & \text { mass flow rate } \\ p & \text { pressure } \\ \omega & \text { pump rotational speed } \\ \text { Subscripts } \\ \text { cond } & \text { condenser } \\ \text { IN } & \text { inlet section } \\ \text { OUT } & \text { outlet section } \\ \text { sat } & \text { saturation (referred to) } \\ \text { Acronyms } \\ \text { CFD } & \text { computational fluid dynamics } \\ \text { CFM } & \text { Coriolis flow meter } \\ \text { FFT } & \text { Fast Fourier Transformation } \\ \text { ORC } & \text { organic Rankine cycle } \\ \text { WOM } & \text { whole ORC model }\end{array}$

\section{References}

1. Landelle, A.; Tauveron, N.; Haberschill, P.; Revellin, R.; Colasson, S. Organic Rankine cycle design and performance comparison based on experimental database. Appl. Energy 2017, 204, 1172-1187. [CrossRef]

2. Macchi, E.; Astolfi, M. Organic Rankine Cycle (ORC) Power Systems, 1st ed.; Woodhead Publishing: Sawston, UK, 2016.

3. Tocci, L.; Pal, T.; Pesmazoglou, I.; Franchetti, B. Small scale Organic Rankine Cycle (ORC): A techno-economic review. Energies 2017, 10, 413. [CrossRef] 
4. Bao, J.; Zhao, L. A review of working fluid and expander selections for organic Rankine cycle. Renew. Sustain. Energy Rev. 2013, 24, 325-342.

5. Wang, Y.; Chen, L.; Jia, B.; Roskilly, A.P. Experimental study of the operation characteristics of an air-driven free-piston linear expander. Appl. Energy 2017, 195, 93-99. [CrossRef]

6. Hou, X.; Zhang, H.; Xu, Y.; Yu, F.; Zhao, T.; Tian, Y.; Yang, Y.; Zhao, R. External load resistance effect on the free piston expander-linear generator for organic Rankine cycle waste heat recovery system. Appl. Energy 2018, 212, 1252-1261. [CrossRef]

7. Burugupally, S.P.; Weiss, L.; Depcik, C. The effect of working fluid properties on the performance of a miniature free piston expander for waste heat harvesting. Appl. Therm. Eng. 2019, 151, 431-438. [CrossRef]

8. Bianchi, M.; Branchini, L.; De Pascale, A.; Melino, F.; Ottaviano, S.; Peretto, A.; Torricelli, N. Application and comparison of semi-empirical models for performance prediction of a $\mathrm{kW}$-size reciprocating piston expander. Appl. Energy 2019, 249, 143-156. [CrossRef]

9. Ichikawa, T.; Yamaguchi, K. On pulsation of delivery pressure of gear pump (in the case of a long delivery pipeline). Bull. JSME 1971, 14, 1304-1312. [CrossRef]

10. Kojima, E.; Shirada, M. Characteristic of fluidborne noise generated by fluid power pump (3rd report, discharge pressure pulsation of external gear pump). Bull. JSME 1984, 27, 2188-2195. [CrossRef]

11. Mucchi, E.; Dalpiaz, G.; Rivola, A. Dynamic behavior of gear pumps: Effect of variations in operational and design parameters. Meccanica 2011, 46, 1191-1212. [CrossRef]

12. Wang, T.; Baker, R. Coriolis flowmeters: A review of developments over the past 20 years, and an assessment of the state of the art and likely future directions. Flow Meas. Instrum. 2014, 40, 99-123. [CrossRef]

13. Vetter, G.; Notzon, S. Effect of pulsating flow on Coriolis mass flowmeters. Flow Meas. Instrum. 1994, 5, 263-273. [CrossRef]

14. Cheesewright, R.; Clark, C.; Hou, Y.Y. The response of Coriolis flowmeters to pulsating flows. Flow Meas. Instrum. 2004, 15, 59-67. [CrossRef]

15. Del Campo, D.; Castilla, R.; Raush, G.A.; Gamez Montero, P.J.; Codina, E. Numerical analysis of external gear pumps including cavitation. J. Fluids Eng. 2012, 134, 081105. [CrossRef]

16. Battarra, M.; Mucchi, E. Incipient cavitation detection in external gear pumps by means of vibro-acoustic measurements. Measurement 2018, 129, 51-61. [CrossRef]

17. Frosina, E.; Senatore, A.; Rigosi, M. Study of a high-pressure external gear pump with a computational fluid dynamic modeling approach. Energies 2017, 10, 1113. [CrossRef]

18. Yoon, Y.; Park, B.-H.; Shim, J.; Han, Y.-O.; Hong, B.-J.; Yun, S.-H. Numerical simulation of three-dimensional external gear pump using immersed solid method. Appl. Therm. Eng. 2017, 118, 539-550. [CrossRef]

19. Kolasiński, P.; Blasiak, P.; Rak, J. Experimental and numerical analyses on the rotary vane expander operating conditions in a micro organic Rankine cycle system. Energies 2016, 9, 606. [CrossRef]

20. Morini, M.; Pavan, C.; Pinelli, M.; Romito, E.; Suman, A. Analysis of a scroll machine for micro ORC applications by means of a RE/CFD methodology. Appl. Therm. Eng. 2015, 80, 132-140. [CrossRef]

21. Bianchi, M.; Branchini, L.; Casari, N.; De Pascale, A.; Melino, F.; Ottaviano, S.; Pinelli, M.; Spina, P.R.; Suman, A. Experimental analysis of a micro-ORC driven by piston expander for low-grade heat recovery. Appl. Therm. Eng. 2019, 148, 1278-1291. [CrossRef]

22. Casari, N.; Suman, A.; Ziviani, D.; Morini, M.; Pinelli, M. Virtual Model for ORC—Whole ORC Modeling: WOM. In Proceedings of the ECOS 2017 30th International Conference on Efficiency, Cost, Optimisation, Simulation and Environmental Impact of Energy Systems, San Diego, CA, USA, 2-6 July 2017.

23. Randi, S.; Casari, N.; Pinelli, M.; Suman, A.; Ziviani, D. WOM: Whole ORC Model. In Proceedings of the 17th International Refrigeration and Air Conditioning Conference at Purdue, Lafayette, IN, USA, 9-12 July 2018.

24. Simerics Inc. PumpLinx's User Manual—V 4.6.4; Simerics Inc.: Bellevue, WA, USA, 2018.

(C) 2019 by the authors. Licensee MDPI, Basel, Switzerland. This article is an open access article distributed under the terms and conditions of the Creative Commons Attribution (CC BY) license (http://creativecommons.org/licenses/by/4.0/). 